\title{
Development of Perdeuterated Polymer Foams for Inertial Confinement Fusion Targets in China
}

\author{
Lin ZHANG, Xuan LUO, Yongheng FAN, Kai DU and Qiang YIN \\ Research Centre of Laser Fusion, China Academy of Engineering Physics, P.O.Box 919-987 Mianyang 621900, China
}

(Received 20 November 2008 / Accepted 6 April 2009)

In this paper, we report the progress made in fabrication of perdeuterated polymer foam materials such as deuterated polystyrene (d-PS), deuterated polyethene (d-PE), and deuterated divinylbenzene (d-DVB) based on the inertial confinement fusion (ICF) research in China. Perdeuterated DVB foams were fabricated using the high internal phase emulsion (HIPE) technique, and perdeuterated PS and PE foams were prepared via the thermally-induced phase separation (TIPS) of polymer solution and freeze-drying. As a result, foams with a deuterium/hydrogen $(\mathrm{D} / \mathrm{H})$ ratio of more than $95 \%$, density of $10-200 \mathrm{mg} / \mathrm{cm}^{3}$, and average porous sizes of 1 $20 \mu \mathrm{m}$ were obtained.

(c) 2009 The Japan Society of Plasma Science and Nuclear Fusion Research

Keywords: perdeuterated polymer foams, high internal phase emulsion, thermally induced phase separation, deuterated polystyrene, deuterated polyethene, deuterated divinylbenzene

DOI: $10.1585 /$ pfr.4.S1005

Deuterated polymer foams as a type of target material can be widely used in high-gain, high-density compression fusion targets, for example, as supporting materials in multilayer targets, as holders of liquid or solid DT layers in cryogenic targets, and so on. They are more essential than other protonated polymer foams because of the following advantages [1]: they are more chemically and physically stable, are nonradioactive, and have a very high proportion of $\mathrm{D} / \mathrm{H}$ (more than 98\%). Therefore, not only can they increase the fusion fuel density of fusion targets but can also improve the wettability of liquid deuterium-tritium (DT).

It is well known that in mild conditions the exchange of deuterium and hydrogen is very difficult. Therefore, the method of fabrication of deuterated polymer foams is similar to that for protonated polymers such as HIPE, TIPS, and Sol-Gel. However, there are few deuterated polymers for the fabrication of low-density foams at present.

Steckle et al. [2] first reported a method to synthesize deuterated DVB (d-DVB). Moreover, they prepared perdeuterated polymer foams with d-DVB by means of the HIPE technique. The synthesis method is quite complex and includes a $\mathrm{D} / \mathrm{H}$ exchange reaction using the high temperature and dilute acid (HTDA) technique. In our work, partially replaced deuterium foams were prepared from deuterated styrene (d-St) and protonated divinylbenzene (DVB) [3] using the HIPE technique. However, the deuterated ratio values of those foams were less than $90 \%$.

As an alterative technique, TIPS could be a competent method for fabricating perdeuterated polymer foams. Combined with freeze-drying, it can be used to prepare many low-density polymer foams such as polystyrene, PE, poly(4-methyl-1-pentene) (PMP), and cellulose. The

author'se-mail: zhlmy@sina.com structure and density of the fabricated foams can be controlled by controlling the concentration of the polymer solution and the freezing rate of the solution. Using these two techniques, PMP, PS, and PE foams were prepared in our laboratory. They had a density of $10-200 \mathrm{mg} / \mathrm{cm}^{3}$ and an average porous size of $1-10 \mu \mathrm{m}$. Meanwhile, d-PS and d-PE were also prepared; they had $\mathrm{D} / \mathrm{H}$ ratios and purities of more than $98 \%$.

Because of different demands of ICF experiments in terms of density, porous size, deuterium content, etc, different foams need to be developed. In this paper, the fabrication methods and performance of d-DVB, d-PS, and d-PE foams are reported.

In 1996, Cameron et al. [4] discussed the structure, properties, and applications of the HIPE technique. Using this technique, we fabricated deuterated polymer foams from perdeuterated styrene and protonated divinylbenzene (DVB). The deuterated polymer foams had densities of $20 \mathrm{mg} / \mathrm{cm}^{3}$ to $100 \mathrm{mg} / \mathrm{cm}^{3}$, average porous sizes of $4 \mu \mathrm{m}$, and $\mathrm{D} / \mathrm{H}$ ratios between $50 \%$ and $90 \%$ (usually not more than $60 \%$ )

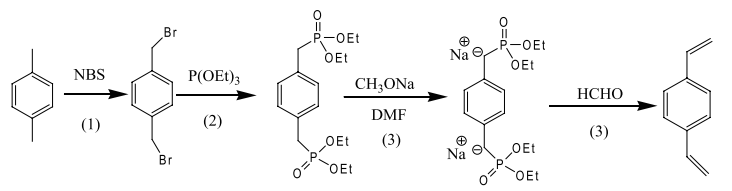

Recently, the deuterated DVB foams with the D/H ratio more than $98 \%$ have been successfully fabricated by Witting-Horne reaction starting with the deuterated xylene. Perdeuterated DVB is synthesized as eq. (1), which contains three-step reactions and has a product yield of about $50 \%$. Figure 1 is an SEM photo of perdeuterated DVB foams with a density of $100 \mathrm{mg} / \mathrm{cm}^{3}$. The $\mathrm{D} / \mathrm{H}$ ratio of the 


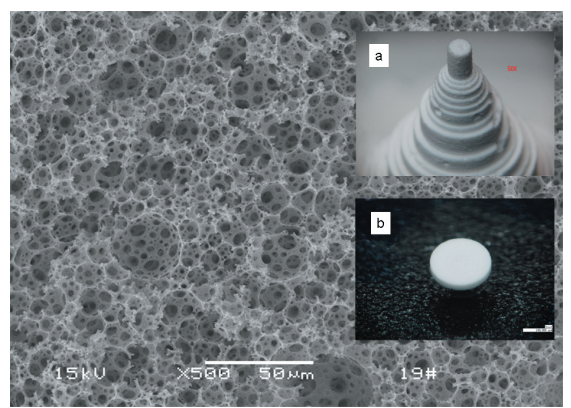

Fig. 1 Deuterated DVB foam with density of $100 \mathrm{mg} / \mathrm{cm}^{3}$ and $95 \% \mathrm{D}$

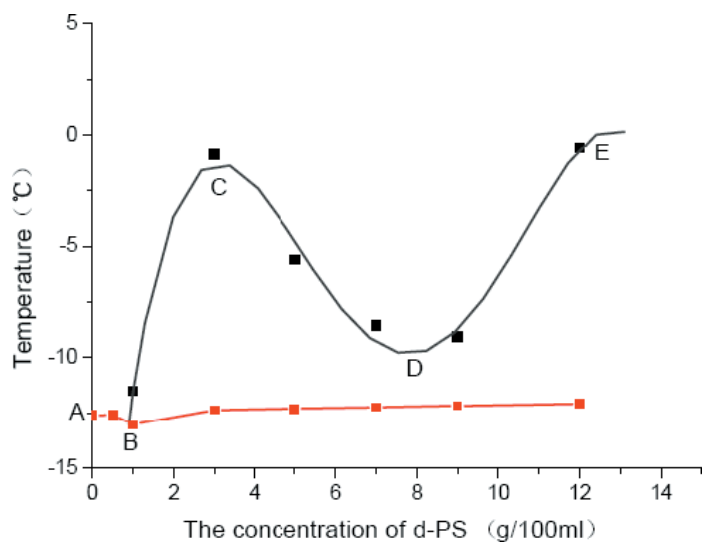

Fig. 2 The phase diagram for d-PS within co-solvent system

foams is about $95 \%$, and their average porous size is about $4 \mu \mathrm{m}$. With an exact lathe, the foams can be easily machined into a cylinder with $100 \mu \mathrm{m}$ diameter and a sheet with $100 \mu \mathrm{m}$ thickness, as shown in Fig. 1 (a) and (b).

As a general technique, TIPS has been widely used to fabricate a variety of polymer foams such as poly(4methyl-1pentene) [5], polystyrene [6], and polyethylene. To obtain a better foam structure, the type of phase separation should be liquid-liquid phase separation with the co-solvent. In our study, the co-solvent system is composed of dioxane and cyclohexane. Figure 2 shows the temperature versus composition phase diagram for fabricating d-PS foams with a co-solvent system.

The curve $\mathrm{ABF}$ is the freezing point curve of the cosolvent. The curve BCD is the bimodal of the liquid-liquid phase separation, and the curve DE is the d-PS crystallization curve of the co-solvent. Figure 3 shows the morphology and structure of d-PS foam prepared using the cosolvent, and the foam has a density of $20-200 \mathrm{mg} / \mathrm{cm}^{3}$, average porous size of $1-10 \mu \mathrm{m}$, and a $\mathrm{D} / \mathrm{H}$ ratio of more than $98 \%$.

Owing to the high $\mathrm{D} / \mathrm{C}$ in its structure, $\mathrm{d}-\mathrm{PE}$ is important in the fabrication of low-density d-PE foams. However, the PE does not dissolve readily and hence is not easily usable in preparing low density foams.

By choosing an appropriate solvent and controlling

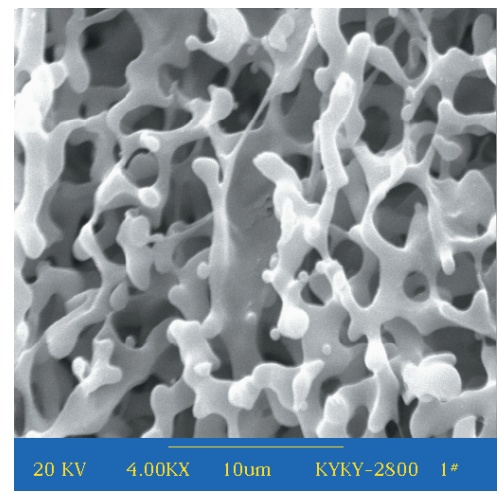

Fig. 3 The morphology and structure of d-PS foam density: $\sim 50 \mathrm{mg} / \mathrm{cm}^{3}$

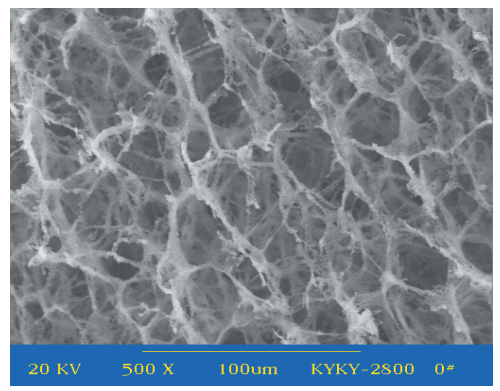

Fig. 4 The structure of d-PE foam density: $\sim 6 \mathrm{mg} / \mathrm{cm}^{3}$

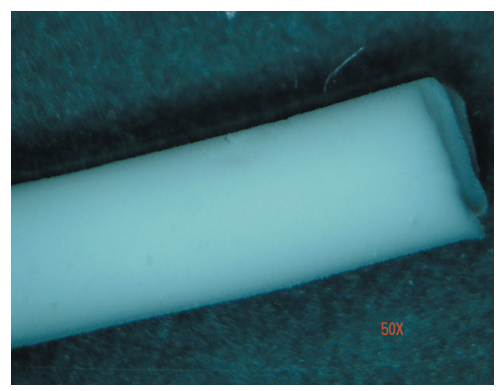

Fig. 5 The morphology of d-PE foam density: $\sim 6 \mathrm{mg} / \mathrm{cm}^{3}$

the quenching rate, we fabricated cylindrical, microcellular foams with a diameter of $2 \mathrm{~mm}$, a length of $20 \mathrm{~mm}$, an average porous size of $20 \mu \mathrm{m}$, and a density of $5-50 \mathrm{mg} / \mathrm{cm}^{3}$ with a $\mathrm{D} / \mathrm{H}$ ratio of $\sim 95 \%$. Figures 4 and 5 show the structure and morphology of d-PE foam with a density of about $6 \mathrm{mg} / \mathrm{cm}^{3}$. Results of mechanical analysis show that the peak strain is $\sim 85 \%$ and that the Young's modulus is $\sim 1700 \mathrm{~Pa}$.

This paper has reported the investigation of three types of perdeuterated polymer foams: d-DVB, d-PS, and d-PE. Perdeuterated DVB foams obtained using the HIPE technique have a density of $10-200 \mathrm{mg} / \mathrm{cm}^{3}$, a deuterated ratio of $\sim 95 \%$, and an average porous size of $4 \mu \mathrm{m}$. Through thermally induced phase separation and freeze-drying of deuterated polymer solution, low-density d-PS foams with 
a density of $20-200 \mathrm{mg} / \mathrm{cm}^{3}$, an average porous size of 1$20 \mu \mathrm{m}$, and a deuterated ratio of more than $98 \%$ have been fabricated. Furthermore, d-PE foams were produced with a density of $5-50 \mathrm{mg} / \mathrm{cm}^{3}$, an average porous size of $20 \mu \mathrm{m}$, and a deuterated ratio of $\sim 95 \%$.

We wish to acknowledge the office of Research Centre of Laser Fusion, China Academy of Engineering Physics, for its financial support of this work.

[1] U. Kubo and H. Tsubakihara, J. Vac. Sci. Technol. A. 4, 1134
(1986).

[2] W.P. Steckle, D.A. Langlois and J.H. Small, Polymer Preprints 42, 41 (2001).

[3] L. Zhang, Y.J. Tang, K. Du et al., Nucl. Instrum. Methods in Physics Research A. 480, 242 (2002).

[4] N.R. Cameron and D.C. Sherrington, Adv. Polym. Sci. 126, 164 (1996).

[5] A.T. Young, D.K. Moreno and R.G. Marsters, J. Vac. Sci. Technol. 20, 1094 (1982).

[6] J.H. Aubert and R.L. Clough, Polymer 26, 2047 (1985). 